\title{
SÍNDROME DE PFAPA- FEBRE PERIÓDICA, ESTOMATITE AFTOSA, FARINGITE E ADENITE
}

\section{ARTIGO ORIGINAL}

OLIVEIRA, Ronan Djavier Alves ${ }^{1}$

ESPÓSITO, Mario Pinheiro ${ }^{2}$

PLACHESKI, Ana Carolina Galindo ${ }^{3}$

PASSOS, Fabio Manoel dos ${ }^{4}$

ANDRAOS, Lorhana Botelho ${ }^{5}$

OLIVEIRA, Ronan Djavier Alves. Et al. Síndrome de PFAPA- Febre Periódica, Estomatite Aftosa, Faringite e Adenite. Revista Científica Multidisciplinar Núcleo do Conhecimento. Ano 05, Ed. 10, Vol. 13, pp. 121-129. Outubro de 2020. ISSN: 24480959, Link de acesso: https://www.nucleodoconhecimento.com.br/saude/sindromede-pfapa

1 Residente em Otorrinolaringologia e Cirurgia Cérvico-Facial, Graduação em Medicina pela Universidade de Cuiabá - UNIC.

${ }^{2}$ Doutor em Otorrinolaringologia pela Faculdade de Ciências Médicas da Santa Casa de São Paulo.

${ }^{3}$ Residente em Otorrinolaringologia e Cirurgia Cérvico-Facial; Graduada em Medicina pela Universidade de Cuiabá - UNIC.

4 Residente em Otorrinolaringologia e Cirurgia Cérvico-Facial; Graduação em Medicina pela Universidade Federal do Paraná - UFPR.

${ }^{5}$ Graduanda em Medicina pela Universidade de Cuiabá - UNIC. 


\section{RESUMO}

A síndrome de febre periódica, estomatite aftosa, faringite e adenite (PFAPA) é uma enfermidade crônica e benigna, caracterizada por episódios recorrentes de febre elevada e periódica, estomatite aftosa, faringite e adenite cervical, frequentemente encontrada em crianças menores de cinco anos de idade. A etiopatogenia é desconhecida e o diagnóstico é clínico e de exclusão. O objetivo do nosso estudo é relatar o caso clínico de uma paciente com síndrome PFAPA, bem como os critérios de diagnóstico e tratamentos de escolha realizados no Hospital Otorrino de Cuiabá MT. Paciente de 25 anos, sexo feminino, com episódios esporádicos de febre alta e odinofagia de longa data. Amigdalas palatinas hipertróficas, grau II com criptas, além de manchas hiperemiadas e dolorosas em lábio inferior. Sinais de refluxo laringo faríngeo na videolaringoscopia. No tratamento, foi proposto o uso de clindamicina conforme antibiograma e prednisolona, além de amigdalectomia programada. Após análise da literatura, fica clara a importância do correto diagnóstico da síndrome e como deve ser considerada precocemente mesmo nas crianças que não apresentem todos os critérios clínicos. Contrariando a prevalência literária, em nosso estudo foi observado uma paciente em idade adulta com persistência do quadro clínico, sem remissão completa dos sintomas. Ainda que obtidos bons resultados com a terapêutica sintomática. $\mathrm{O}$ tratamento médico mais eficaz é a corticoterapia que, todavia, não previne recorrências. Já em longo prazo, julga-se como opção, a cirurgia de amigdalectomia.

Palavras-chave: Febre Recorrente, Faringite, Estomatite Aftosa.

\section{INTRODUÇÃO}

PFAPA - (Periodic Fever, Aphtous Stomatitis, Pharyngitis and Cervical Adenitis), traduzida como Febre Periódica, Aftas Orais, Faringite e Adenite Cervical. A PFAPA é a síndrome autoinflamatória pertencente ao grupo mais comum das síndromes febris recorrentes na infância, apesar de sua prevalência exata não ser conhecida e só ser identificada como afecção clínica em 1987. 
Trata-se de uma doença rara, não genética, crônica, sintomática antes dos cinco anos de vida e, na maioria dos pacientes o quadro se resolve, espontaneamente, antes dos 10-12 anos. Entretanto, pode prolongar-se ou iniciar-se na vida adulta do paciente.

A prevalência é variável em todo o mundo, e não há dados estatísticos da doença no Brasil. É diagnóstico diferencial importante com muitas infecções em crianças de idade pré-escolar e, com certeza, todo médico encontrará alguns casos de PFAPA durante sua carreira.

\section{RELATO DE CASO}

Paciente de 25 anos, sexo feminino, vem ao consultório em junho de 2018 queixandose de odinofagia há 6 dias, tosse seca, episódios esporádicos de febre não aferida e uso de nimesulida desde o início dos sintomas, sem melhora. Ao exame físico: oroscopia com amigdalas palatinas grau 2, criptas hipertróficas com secreção purulenta e hiperemia de orofaringe. Além de manchas hiperemiadas e dolorosas em lábio inferior, sugestivas de estomatite. Foi realizada a videolaringoscopia que evidenciou sinais de refluxo laringo faríngeo e amigdalite crônica. Em setembro e outubro de 2018 retorna ao consultório com as mesmas queixas de odinofagia sem melhora, picos febris, aftas orais e sintomas de dispepsia e regurgitação, que reforçam a hipótese de refluxo gastroesofágico. Em março de 2019 paciente retorna devido as amigdalites de repetição, estomatite, piora das aftas orais de longa data, febre associada à artralgia, mialgia e cefaleia. No exame físico: orofaringe com amigdalas palatinas grau 2, com criptas, hipertróficas e lesões aftoides em loja amigdaliana, amigdalas palatinas e lingual. Foram solicitados cultura e antibiograma de orofaringe. Resultado da cultura: Staphylococcus aureus e contagem de colônias 106 UFC. Ao antibiograma, concentração inibitória mínima menor que 0,5 para Ceftarolina, Ciprofloxacina, Clindamicina, Oxacilina, Penicilina G, Trimetoprim-Sulfametoxazol e Vancomicina. O tratamento de escolha foi clindamicina e prednisolona, evoluindo com melhora clínica importante, sem remissão completa dos sintomas, fora proposto cirurgia de amigdalectomia das tonsilas palatinas para o caso. 


\section{DISCUSSÃO}

Síndrome de febres periódicas com estomatite aftosa, faringite e adenite (PFAPA) é uma síndrome de febre autolimitada que se manifesta tipicamente entre crianças de 2 a 5 anos de idade. Entretanto, atualmente, sabe-se que pode atingir crianças mais velhas e, excepcionalmente, adultos. No norte da Itália, como os estudiosos Bueno; Paiva; e Carvalho (2019) analisaram, a incidência foi de aproximadamente 0,4 casos/1000 crianças/ano. Ademais, o estudo não observou a predileção por grupos étnicos, entretanto, foi considerado que houve leve predomínio para com o sexo masculino.

Fonseca e Cherubini (2015) compreenderam que cada episódio febril, de origem indeterminada, tem duração aproximada de três a seis dias e, no que diz respeito à periodicidade, os diferentes trabalhos publicados estabelecem uma variação de três a oito semanas (média de 28 dias). A febre elevada $\left(39-40,5^{\circ} \mathrm{C}\right)$ não responde a antitérmicos e anti-inflamatórios. A faringite exsudativa e eritematosa está presente em até $90 \%$ dos pacientes, seguida por linfadenomegalia cervical em até $75 \%$ e aftas orais em até $50 \%$. Quanto à estomatite aftosa, as lesões se localizam, predominantemente, na região anterior da cavidade oral, são menores que $3 \mathrm{~mm}$, em pequenas quantidades e poupam as gengivas. Essas características permitem excluir outras condições que apresentam aftas, como a herpangina e a gengivoestomatite herpética. Outros sintomas menos frequentes são cefaleia, mal estar, calafrios, mialgia, artralgia, dor abdominal, náusea e vômitos. Os pacientes são saudáveis entre as crises, não havendo associação com outras doenças ou comprometimento no desenvolvimento infantil.

Os pesquisadores Vanoni; Teodoropoulou e Hofer (2016), entenderam que em adultos, é comum a manifestação da síndrome na infância, com resolução e retorno na idade adulta por volta da segunda década de vida, ocorrendo o diagnóstico, geralmente, na terceira década. Comparando adultos e crianças com síndrome PFAPA, é possível notar que há uma frequência menor de artralgias e mialgias, e maiores lesões aftosas e manifestações associadas aos episódios febris quando associadas ao último grupo. 
Moreira (2012), em sua pesquisa entende que a etiologia e fisiopatologia da PFAPA ainda são desconhecidas, persistindo a dúvida sobre se tratar de doença infecciosa ou disfunção imunológica. Embora as causas genéticas não tenham, ainda, sido determinadas, esta síndrome tende a ser agrupada com as síndromes de febres hereditárias. A presença de mais de um caso na família sugere origem poligênica ou herança complexa. A hipótese de resposta anormal da imunidade inata, com aumento de interleucina (IL)-1 beta, como ocorre em muitas doenças autoinflamatórias monogênicas, é a patogenia mais apoiada pelos estudos atuais. $O$ agente infeccioso na etiologia da PFAPA é desconhecido, mas fatores ambientais podem estar associados a fatores imunológicos, contribuindo para a doença em um indivíduo geneticamente susceptível.

O critério diagnóstico para PFAPA mais utilizado é o critério de Thomas (Tabela 1), estabelecido em uma coorte de 94 pacientes com PFAPA em 1999, sendo este uma modificação do critério de Marshall de 1987, data da descrição da doença.

\section{FIGURA 1: TABELA}

Tabela 1

Critérios diagnósticos para PFAPA na idade pediátrica ou idade adulta

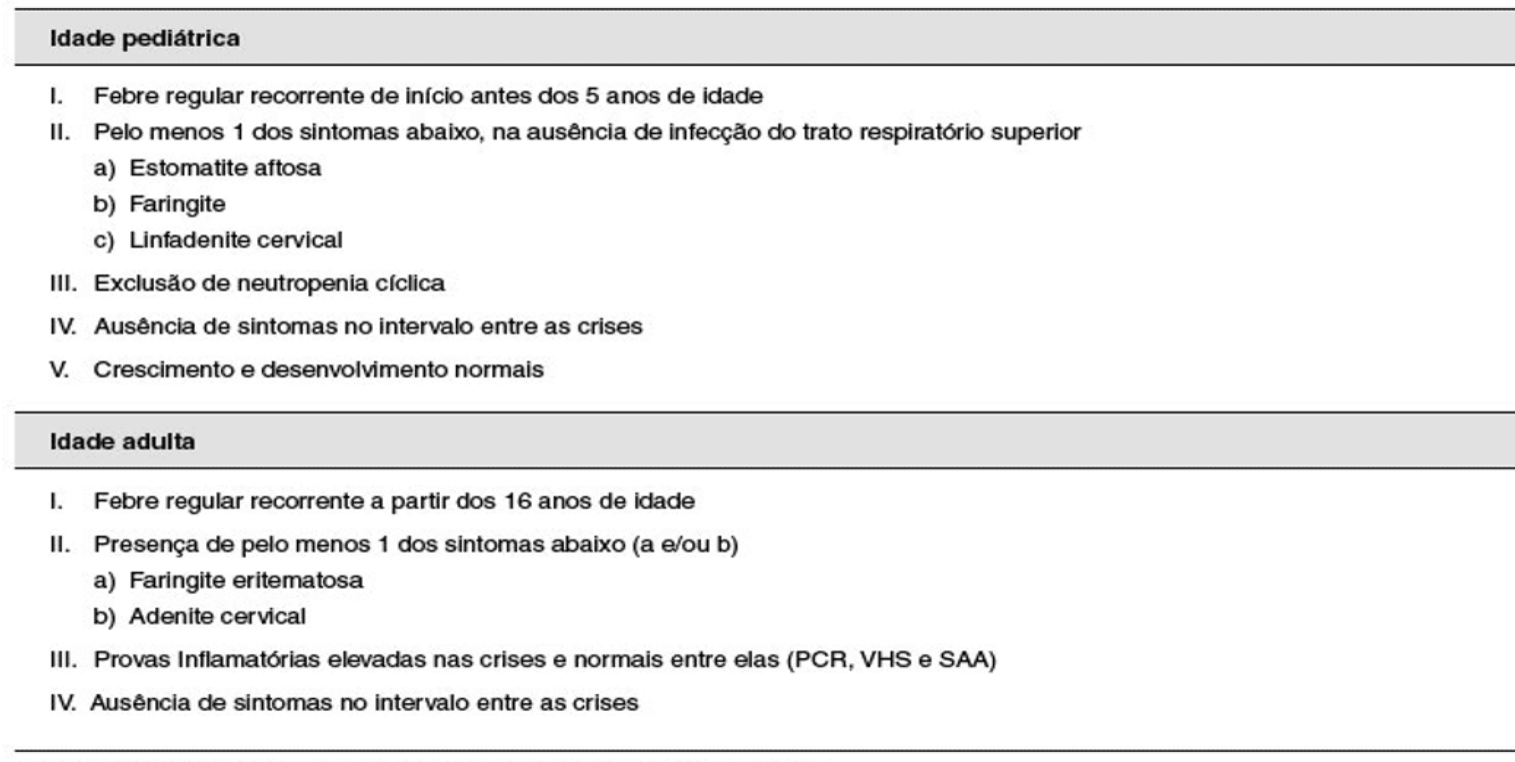

PFAPA = Síndrome PFAPA (febre periódica, aftas orais, faringite $\Theta$ adenite cervical).

Fonte: Revista Oficial da Associação Brasileira de Alergia e Imunologia ASBAI. (2019) 
Sampaio e Marques (2011) compreendem que os achados laboratoriais são inespecíficos. Durante os surtos febris, geralmente, há moderada leucocitose com predomínio de neutrófilos, monocitose, aumento da velocidade de hemossedimentação e da proteína C reativa (reagentes de fase aguda), com normalização desses marcadores nos intervalos entre as crises. É importante a sorologia para citomegalovírus, herpes e vírus de Epstein-Barr em pelo menos um episódio. Neutropenia e outros sintomas como: diarreia, erupção e tosse, não parecem estar presentes, sugerindo a necessidade de excluir outra doença.

FIGURA 2 - OROFARINGE

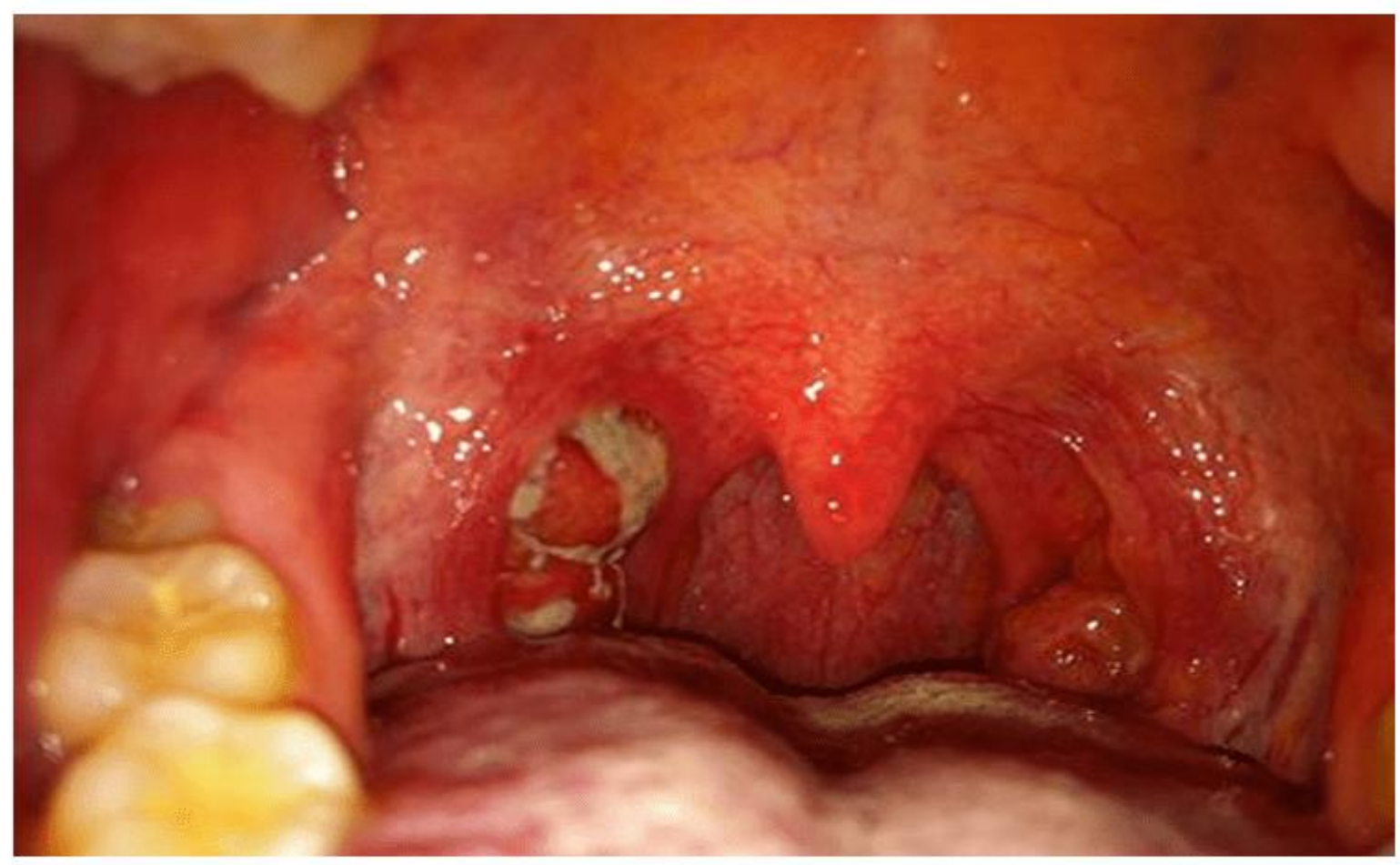

Fonte: autoria do autor, 2020.

Sampaio e Marques (2011), ainda afirmam que a PFAPA tem um diagnóstico diferencial importante de outras infecções em crianças de idade pré-escolar. Doenças febris com sintomatologia similar, principalmente, faringoamigdalites virais e bacterianas, devem ser excluídas pela identificação de sinais de infecção do trato respiratório superior ou culturas de orofaringe positivas. Os pacientes com síndromes hereditárias febris podem preencher os critérios diagnósticos de PFAPA, tratando-se 
também de uma doença autoinflamatória, mas que não está associada à mutação genética. Portanto, alguns pacientes devem ser selecionados e investigados clínica ou geneticamente para outras síndromes de febre periódica. O principal diagnóstico a ser excluído é a neutropenia cíclica, já que os pacientes cursam com febre, faringite, estomatite e outras infecções bacterianas a depender da gravidade da neutropenia, que, em geral, dura de 3 a 10 dias e se repete em intervalos de aproximadamente 21 dias.

A abordagem terapêutica e prognóstica ainda é controversa, mas visa remissão dos episódios febris e melhora da qualidade de vida. Embora não exija tratamento específico, os glicocorticoides são altamente eficazes no controle das crises. Uma única dose de prednisona (1-2 $\mathrm{mg} / \mathrm{kg})$ ou de betametasona $(0,1-0,2 \mathrm{mg} / \mathrm{kg})$ logo no início do episódio, reduz a febre em menos de seis horas, bem como a maioria dos sintomas associados em 48 horas, exceto a estomatite aftosa (manifestação mais lenta para responder). Se uma dose não for eficaz, uma segunda dose pode ser administrada no dia seguinte $(0,5-1 \mathrm{mg} / \mathrm{kg})$. Em adultos, a prednisona em dose de $60 \mathrm{mg} /$ dia administrada precocemente, melhorou dramaticamente o quadro sintomático.

Contudo, a utilidade dos esteroides é questionada. Devido a recorrência, o uso de corticosteroides em demanda parece ter o mesmo efeito imunossupressor que uso crônico. O intervalo assintomático entre os episódios pode ser reduzido em $25 \%$ a $50 \%$ dos casos. Além disso, a administração de corticosteroides não previne futuros surtos de febre. A resposta ao corticoesteroide pode ser usada como prova terapêutica, distinguindo os episódios febris de PFAPA, daqueles observados em outras doenças autoinflamatórias febris que geralmente não manifestam este tipo de resposta.

Para os pacientes não respondentes à corticoterapia, uma alternativa é a cimetidina, que parece aumentar a síntese de interferon, além de modular a liberação de citocinas e fator quimiotático de leucócitos envolvidos na síndrome PFAPA. A colchicina pode ser uma opção interessante para pacientes com episódios frequentes. Seu uso profilático é baseado nas semelhanças clínicas e laboratoriais entre a síndrome 
PFAPA e a febre familiar do mediterrâneo, além da experiência no tratamento desta com a colchicina. (BUENO; PAIVA e CARVALHO, 2019)

Muitos pacientes com síndrome PFAPA possuem níveis séricos baixos de vitamina D. Alguns autores utilizaram a reposição de vitamina $D$ como forma de tratamento, obtendo redução importante no número de episódios febris. Todavia, ainda não é possível afirmar que a vitamina $\mathrm{D}$ seja eficaz, pois faltam estudos de grandes coortes de pacientes.

Recentemente, Vanoni; Teodoropoulou e Hofer (2016) compreenderam que os inúmeros estudos mostraram a eficácia da tonsilectomia em pacientes com PFAPA, sobretudo em casos de alta recorrência e com curto intervalo de tempo intercrises, além dos casos com contraindicação ou refratários ao tratamento clínico. A cirurgia, na maioria dos pacientes, elimina as crises febris recorrentes, sendo, atualmente, considerada terapia definitiva para a PFAPA.

Em contraposição, a prevalência da doença, em nosso estudo foi observado uma paciente em idade adulta e de sexo feminino, com persistência do quadro clínico. Obtivemos bons resultados com a terapêutica sintomática, sem remissão completa dos sintomas, sendo proposta a cirurgia de amigdalectomia.

\section{CONSIDERAÇÕES FINAIS}

Não há como negar que se trata de uma patologia infrequente e cujo reconhecimento pode ser difícil. Por isso, em análise literária, é de suma importância dar o correto diagnóstico da síndrome, mesmo na criança que não apresente todos os critérios clínicos, eliminando possíveis diagnósticos diferenciais.

Uma vez confirmada, o profissional deve tranquilizar e orientar os familiares, esclarecendo-os sobre a diminuição da recorrência dos quadros com o avanço da idade.

Em contrapartida, em nosso estudo foi observado uma paciente de 25 anos de idade, sem remissão completa dos sintomas apesar da abordagem terapêutica 
conservadora. O tratamento médico primário de escolha é a corticoterapia que, entretanto, não previne futuras recorrências. A cirurgia de amigdalectomia tem obtido resultados satisfatórios, e a remoção das tonsilas palatinas é considerada curativa, sendo necessário manter acompanhamento pós-operatório para confirmação da remissão da doença.

\section{REFERÊNCIAS BIBLIOGRÁFICAS}

BUENO, Laniel Aparecido; PAIVA, Débora Magalhães; CARVALHO, Paulo Henrique Pimenta. Síndrome PFAPA: Diagnóstico e Tratamento na Atenção Primária à Saúde. Revista Brasileira de Medicina, Família e Comunidade, Minas Gerais, 2019. Disponível em: < https://www.rbmfc.org.br/rbmfc/article/view/1815> Acesso em: 08 de out. de 2020.

FONSECA, Alisson; CHERUBINI, Karen. Aspectos de interesse clínico sobre a síndrome PFAPA (febre periódica, estomatite aftosa, faringite e adenite). Scientia Médica, Porto Alegre, 2005. Disponível em: < https://revistaseletronicas.pucrs.br/ojs/index.php/scientiamedica/article/view/1546/0> Acesso em: 08 de out. de 2020.

MAGALHÃES, Claudia Saad. Diretrizes de conduta e tratamento de síndromes febris periódicas: síndrome de febre periódica, estomatite aftosa, faringite e adenite. Revista Brasileira de Reumatologia, São Paulo, 2016. Disponível em: < https://www.scielo.br/pdf/rbr/v56n1/0482-5004-rbr-56-01-0052.pdf> Acesso em: 08 de out. de 2020.

MENDONÇA, Leandro Oliveira; DIAS, Gabriella Mello Fontes Silva; SOUSA, Natália Cândido; FRANCESCO, Renata; CASTRO, Fábio Fernandes Morato; BARROS, Myrthes Toledo. Síndrome PFAPA (febre periódica, aftas orais, faringite e adenite cervical) em crianças e adultos. Arquivos de Asma Alergia e Imunologia, São Paulo, 2019. Disponível em: < http://aaai-asbai.org.br/detalhe_artigo.asp?id=965> Acesso em: 08 de out. de 2020. 
MOREIRA, Filipa; PEREIRA, Gabriel; MARÇAL, Nuno; GUIMARÃES, Joana; MIRANDA, Daniel. Síndrome PFAPA - Caso clínico. Revista Portuguesa de Otorrinolaringologia e Cirurgia Cérvico-Facial, Braga, 2012. Disponível em: < https://www.journalsporl.com/index.php/sporl/article/view/95> Acesso em: 08 de out. de 2020.

SAMPAIO, Isabel; MARQUES, José Gonçalo. Síndrome de febre periódica, estomatite aftosa, faringite e adenite - Análise retrospectiva de 21 casos. Acta Médica Portuguesa, Lisboa, 2011. Disponível em: <actamedicaportuguesa.com> Acesso em: 08 de out. de 2020.

VANONI. Frederica; THEODOROPOULOU, Katerina; HOFER, Michaël. PFAPA syndrome: a review on treatment and outcome. Pediatric Rheumatology, Lausanne, 2016. Disponível em: $<$ https://pedrheum.biomedcentral.com/articles/10.1186/s12969-016-0101-9> Acesso em: 08 de out. de 2020.

Enviado: Agosto, 2020.

Aprovado: Outubro, 2020. 